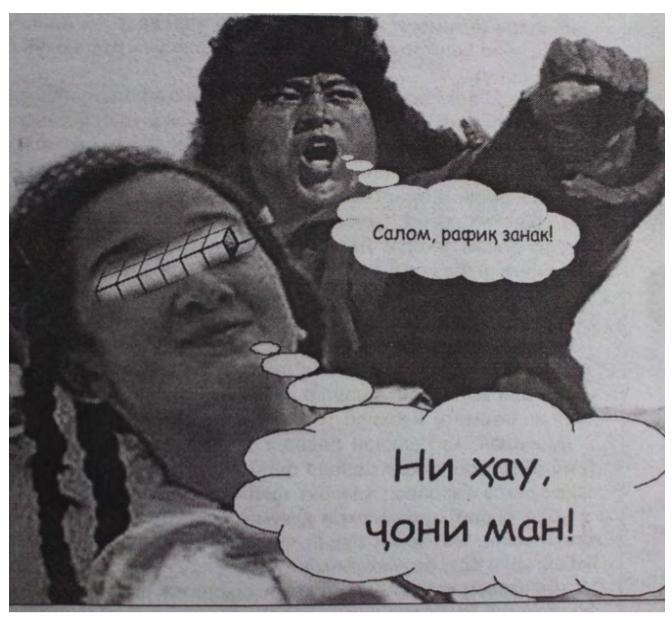

\section{In the Interstices} of Patriarchal Order

\author{
Spaces of Female Agency \\ in Chinese-Tajik Labour \\ Encounters
}

Irna HOFMAN

Although there has been an increasing focus on actor agency in the context of China's growing global presence, encounters between Chinese and local people in Central Asia are still relatively unexplored, and even when they are in the spotlight, the focus is often on the agency of local elites. To fill this gap, this essay examines personal and labour relations in Chinese agribusinesses in Tajikistan, focusing in particular on the interactions between Chinese men and Tajik women.

\begin{abstract}
'A Chinese husband:
has the husband crisis been solved?' Image accompanying an article in a popular newspaper in 2012 (Ilhom 2012).
\end{abstract}

'What do you want? Shall I give you some cotton? Here!' the young woman said to the Chinese worker, who passed by the fields to check the progress of cotton picking. 'No, no. You, come, tonight, tonight,' the man answered, using Tajik words. She smiled and shouted: 'With whom? What would my husband think?!'

- Fieldwork observations, southwest Tajikistan, 25 October 2020

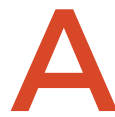

lthough actor agency in the context of China's growing global presence is now the centre of considerable academic attention, China-Central Asia encounters, particularly with regard to local dynamics, remain relatively unexplored. It is a delicate field involving large Chinese loans and investments, debt, the Uyghur question, and complicated elite networks. Tajikistan offers a good example of these dynamics. With their numbers growing since the past decade, a huge variety of Chinese actors are now navigating their way in the country. They mingle, coalesce, or conflict and compete with local societal actors in various ways, triggering responses of various kinds and demonstrating the uneven ability to exercise agency by all involved.

In this essay, I draw attention to female agency and the modes of subversion undertaken by women working for Chinese agribusinesses in Tajikistan. ${ }^{1}$ Notably, the agricultural sector is one of the few sectors in rural Tajikistan with Chinese investment in which Chinese men regularly interact with Tajik women. This contrasts with construction or road-building sites in which women are usually not actively engaged-at least not beyond what is often seen as typical women's work. I reveal female agency in highly asymmetric labour and gender relations by demonstrating how agency is exercised in different ways: a) to challenge the domestic 
patriarchal order; and b) to express discontent regarding labour conditions. In so doing, I also shed light on the multiplicity of perceptions of 'China' in Tajikistan, while not neglecting the fact that anxiety concerning the presence of Chinese actors surfaces, and segregated work and living patterns continue, all while the China discourse becomes more differentiated by increased personal connections and individual interdependencies.

\section{The China Discourse in Tajikistan}

In the wake of the breakdown of the Soviet Union, China's relationship with Tajikistan deepened, solidifying further after the inception of the Belt and Road Initiative in the mid-2010s. As a result, a plethora of Chinese actors have settled and started working in the country, involving and triggering various kinds of distant and intimate interconnections. Increasing personalised contacts have meant shifts in the way Chinese people are seen and result in affection as well as antipathy (see also Peyrouse 2016).

Perceptions of China in Tajikistan are shaped by various dynamics that were at play over the past decade: a border shift, land acquisitions, mineral exploration, an influx of Chinese consumer goods, and the arrival of predominantly male migrants, triggering fears of a loss or even extinction of Tajik and Muslim identities in the case of sexual intercourse and marriages. While all these circumstances have boosted anti-Chinese sentiment, this is not the entire story and there are other, more positive perceptions that cannot be solely attributed to the Chinese state's attempts at enhancing its soft power. Whereas the Chinese state provides generous grants to the Tajik state, scholarships to local youth, and medical supplies to society at large in the context of Beijing's 'health diplomacy', face-to-face interactions in various locales are what result in a patchwork of perceptions.

This nuance is often missing in discussions of the Chinese presence in the country. Attention to agency in China-Tajikistan relations tends to concentrate on state and elite actors. When it comes to the grassroots, it is generally assumed that ordinary citizens have little choice but to passively accept the Chinese presence and have no alternative to taking on jobs in Chinese-run companies. Such assumptions, however, neglect local agency, as well as the fact that the agency of Tajik actors is, to a large extent, shaped by domestic state-society relations.

\section{Social Networks and Labour Relations on Chinese-Run Farm Holdings}

The countryside in Tajikistan is a microcosm where it is possible to see these encounters between Chinese and local actors play out. In most of rural Tajikistan, social networks fulfil controlling roles, and also function as ways to solve disputes and discipline labour. Authorities and chairmen of large farm holdings tend to instrumentalise local social networks to mobilise labourers, particularly at peak moments of the agricultural season. Inserting themselves in this context, Chinese companies have also figured out that local social networks in rural Tajikistan constitute an efficient way to guarantee labour supply.

Relations and tasks on these farms are highly gendered. Most male teams tend to be formed by a relatively permanent group of men in technical positions who work and often also reside together throughout the agricultural season. In contrast, women primarily deal with the manual weeding and harvesting of crops, and their work is most often casual and group membership fluctuates. As a result, different dynamics take shape in female and male work brigades, which, in turn, affects intragroup solidarity (for similar observations in Ethiopia, see Fei 2020). In the case of women's groups, it is often only their brigadier (usually also female) who has a long-term, though always seasonal, labour contract with the enterprise, which invariably includes some quite abstract clauses detailing 
labour conditions that are generally absent in most local labour arrangements.

At first sight, labour recruitment and interactions in fields belonging to Chinese companies are not that different from those that can be found among local farmers. As on local farms, there is a hierarchy in the management. At the lowest level, a female brigadier is recruited as an intermediary who mobilises and manages labourers. These female leaders are also responsible for administering labour and paying out wages. Local male managers then supervise a few female brigadiers and are, in turn, supervised by one or two Chinese male managers. While the hierarchy may be effective for the employers to procure and control workers, it also puts workers at risk of fraud. Although farmers and farm labourers maintain that Chinese companies pay up every cent (tin) for raw cotton or work (unlike some local farmers and companies), I observed that, lower in the hierarchy, brigadiers sometimes withhold part of the payment to their brigade members. In such cases, individual women cannot easily address Chinese superiors-a situation that points to the way in which reliance on local networks can serve to reaffirm power hierarchies.

On local as well as Chinese farm fields, masculinity dominates, as men control the physical labour of women. However, interactions and power dynamics are different in the two settings. On locally owned farms, an elder male farm chairman tends to be present to maintain patriarchal order and supervise women's work. In contrast, on Chinese fields, local male elders are absent and young Tajik men, aged mostly in their twenties or early thirties, guard the fields, sometimes accompanied by one or two Chinese workers. The presence of non-local male translators may put pressure on the women at work, but the absence of seniority impacts on gender interactions in the fields and in a way that reverberates out to local society at large.

\section{Honour and Pride}

In Tajikistan, seniority is particularly articulated in relation to family honour (nomus), which is consid- ered a fundamental value (Harris 2004; Behzadi 2019). The ingrained importance of honour and pride, in tandem with patriarchal order and social control, disciplines women's private and public behaviour. This includes interactions with strangers, such as non-local Tajik and Chinese men. In most families, Tajik women are fated to undertake the roles of mothers, and carers, responsible for household chores. The way in which they act outside the home can affect a family's possibilities to marry off their offspring and thus has a real impact on the family's future prosperity. While divorce is becoming more common, separating still stigmatises both the woman involved and her family. Many consider marriage to be essential for both women's identity and their protection. It is also worth noting that for many men and women, marriage is seen as a means of protection.

However, as Negar Elodie Behzadi (2019) has described, women's exclusion from the public sphere can, to an extent, be attributed to the importance of male honour in society. Not all women gain permission from their family to work outside the home, where they might interact with unknown men. As a result, women engaged in work outside the home have to walk a tightrope between shame and pride, exploitation and remuneration, and family honour and stigmatisation. Sometimes women taking the lead, such as female farm brigadiers, gain local respect as strong and active women, but they may also be condemned or disrespected for their liberal way of engaging with men, by both female and male neighbours. Rumours often circulate about women working in public spaces-including not only in Chinese companies but also in Tajik teahouses-being divorced or widows, both of which are translated into beva in Tajik language-a term that carries a negative connotation.

Single women in Tajikistan may enjoy more autonomy in choosing how they earn an income, but in many cases their extended family still exerts substantial social control due to the considerations for the family's prosperity mentioned above. For married young women and unmarried daughters, the negotiating, bargaining, and decision-making over female labour and fieldwork take place in the private realm, over or after dinner. Whether or 
not women are allowed to work outside the home depends often not only on their husbands (present or abroad), but also on the parents-in-law. Women's public engagement and their ability to do so are also related to one's life stage, as are modalities of agency. When women, either married or unmarried, are permitted to engage in the labour market, out of perceived financial necessity or otherwise, the farm work-which is outside the private sphere and outside direct patriarchal control-allows them a space in which to socialise. They can enjoy time among other female workers to gossip, chat, talk about the latest village news, last night's TV soap series, children, and men. Some may even flirt, as the vignette at the beginning of this essay illustrates. Some women can and do choose to do this despite exploitative labour relations.

Whereas some women prefer to stay at home to engage in caring and unpaid domestic work , work other than household chores is also valued highly as it allows women to experience an identity other than that of mother and carer, breaking them out of their isolated position. Their identity changes from wife, daughter, or sister-in-law, to independent worker. However, in so doing, they must strike a balance, as noted above, between shame and honour, agency, and self-respect. By acknowledging this and discerning the more refined ways in which agency-and sometimes contestation and resistance-are expressed, we can, instead of solely addressing the vulnerability of women, also recognise and appreciate their dignity and modalities of agency other than those commonly attended to. Women are not only or always passive actors subject to the power plays of a male authority. Their wishes and desires shape their actions and choices, even if their ability to chase their goals is restricted.

\section{Intermarriages}

Working for Chinese companies exposes women to intercultural interactions that make clear the cultural differences in gender and power relationships. Vis-a-vis foreign men, particularly when relationships of dependency are reversed such as in the interaction between Tajik female translators and Chinese men, Tajik women may come to appreciate a sense of self-esteem more strongly. Intercultural interactions may also trigger interest, curiosity, and desire, in spite of all the possible negative repercussions this might have for a woman's status. There exist great obstacles to personal relationships between Tajik women and Chinese men, which go well beyond cultural differences and language barriers. Tajik women may find themselves having to contest patriarchal bargains (Kandiyoti 1988), as there is a strong social resistance to them having personal relationships with Chinese men.

As such, relationships and labour encounters between Tajik women and Chinese men offer a glimpse of the resistance of local patriarchal society to these interactions. As most Chinese actors in Tajikistan are male, female Tajik translators-who most often have studied for a year or more in China-translate for and interact predominantly with male Chinese colleagues and bosses. While the potential financial rewards of working for a Chinese company may convince parents and/ or partners to support this type of work, these workers are often the recipients of attention in the public sphere. Intermarriages between Tajik women and Chinese men are even more controversial. This type of marriage is rare and mostly confined to urban areas. While the limited number of marriages between Chinese and Tajik individuals is partially due to the limited interaction between the two groups, stigmatisation is a more important factor inhibiting this type of relationship. As one Chinese friend married to a Tajik woman recently told me: 'If a Tajik woman and a Chinese man are married, it is very embarrassing for them to walk on the street.'

Only sporadically does one hear of personal relationships between Chinese men and Tajik women in the countryside. Indeed, such cases are so rare and controversial they become widely discussed topics. For instance, when I raised the taboo around Tajik-Chinese romantic relations in a conversation with a Tajik female friend and her husband, my friend commented: 'The divorced woman living next door was close with one of the Chinese labourers of the Chinese agribusiness 
nearby, Mr Bean.' 'Mr Bean?' I asked, raising my eyebrows. 'Yes, Mr Bean, that's the man's name, it's a Chinese name.' 'No, I don't think so,' I answered, and referred to Rowan Atkinson's popular character. My friend's husband started laughing. 'Well, never mind,' my friend continued, as she did not know who had come up with the name. She explained that the divorced female neighbour, who lived with her elderly father and the family of her older brother, had been forced to stop working in the fields of the Chinese agribusiness after this older brother-aged in his fifties and living in Russia-was informed about the gossip about his younger sister.

The issue of relationships and marriages between Tajik women and Chinese men continues to spark substantial debates also at the national level. Given the sex ratio resulting from male outbound labour migration, some fear that single women will opt for marrying a Chinese male labour migrant in the absence of Tajik men and the discourse of a 'husband crisis' has emerged. Marriages between Tajik women and Chinese men are perceived as more problematic than other intercultural relationships, particularly with regard to a feared loss of Tajik identity and Muslimhood, and the idea that most contact concerns prostitution. To prevent Tajik women from engaging with Chinese men, as well as to prevent prostitution, voices in Tajik society call for legalisation of polygyny (on polygyny, see also Thibault 2018).

The controversies concerning prostitution and Chinese-Tajik relationships recently came to the fore after two incidents. First, a Chinese smallholder farmer, living in solitude next to his farm fields in a peri-urban area close to the Tajik capital city, Dushanbe, and whom I had visited earlier in 2020, was killed. The news came as a great shock to some within the Chinese resident community in Tajikistan. Because there was no meaningful support from the Chinese Embassy, some in the Chinese community mobilised to take care of the funeral and communicate with the man's relatives back in China. According to local media and authorities, the man was killed by a young Tajik woman who worked in his fields and with whom he used to have sexual intercourse. It was said that one night she had refused and, in a fight, hit him with a heavy item, eventually causing his death. While Tajik people in the vicinity remained relatively silent, the case provoked debate in the Tajik media. That the woman was engaged in sexual intercourse out of financial need was taken for granted in local reactions on social media and the news triggered outspoken expressions of antiChina sentiment, as well as accusations against the woman's family for their supposed lack of care that led to her bedding her boss. And, again, it was suggested to legalise polygyny, as it would offer protection against prostitution and/or marriages to Chinese men. The second incident happened more recently and concerned an article posted online by Chinese media about alleged details on prostitution in various countries, including Tajikistan (see Muhammadi 2021). The fact that it was taken up and received quite some attention exemplify that Chinese-Tajik relationships are contentious, more so than other intercultural relationships, and that a part of Tajik society considers the growing presence of Chinese actors in Tajikistan as a threat to Tajik women, in addition to other perceptions.'

\section{Challenging Labour Relations}

Going back to the farms described earlier in this essay, Tajik women in rural areas also find ways to exert their agency when working for Chineseowned agribusinesses. Interactions between Chinese men and Tajik women in rural Tajikistan have increased since Chinese agribusinesses started farming in the country's southwest. Women in poverty-stricken rural areas of the country often have little choice but to engage in manual farm work, which is locally understood as typical women's work, and the cotton fields of Chinese-run farm holdings offer them an opportunity. The wage they receive is necessary for family survival and, in most localities, the Chinese agribusinesses pay slightly more than do local farmers. Although the work is perceived as tough, protests or demands remain limited. People rarely resign, simply because of the need to make a living. After all, protests might result in layoffs. 
However, female workers do express discontent-and demonstrate sometimes effective forms of agency-in other ways. First, silent but very effective forms of protest that women in Tajikistan have been using are voting with their feet and foot dragging-two instances of Scottian 'everyday resistance' (Scott 1985). One group of women in the locality in which I resided refused to work on the Chinese farm fields until the company management met their demands. As one of them told me:

\section{We are not going to work until they raise the payment and construct a shaded place for lunch time ... It is terribly hot out there, and there is also no clean drinking water. We discussed this in our brigade and agreed all together to stay away.}

In this case, the refusal to work did not last long, as the workers stood to lose too much because their employer used a system of delayed remuneration (they were paid only every five or 10 working days), which binds labourers and enforces commitment-a method also usually applied by locally owned businesses. In fact, delayed remuneration and piece-rate payments as means to control the quality of labour severely constrain the ability of workers to resort to this method of protest. In particular, foot dragging may eventually put the women on the losing end. For instance, when Chinese workers were not satisfied with the quality of work on the cotton fields, they demanded a brigade redo the work.

Besides voting with their feet and foot dragging, another way in which Tajik female workers exert their agency is pilfering. When it comes to male labourers, small-scale theft is of agricultural inputs, such as small amounts of precious cotton seed. In the case of women, pilfering of raw cotton in the evenings or during regular picking hours appears to be a frequent act. Women hide it in separate bags or under their kurta (dress) during work. When pilferers are caught in the act, local men or women may protect their fellow villagers, but Chinese management may fine a brigadier by withholding a day payment. To prevent pilfering, Chinese companies have been forced to intensify surveillance around harvest time, day and night. During regular work hours, many young men patrol the fields. According to my interviewees, this frequent smallscale theft of cotton-a phenomenon I observed in different localities in southwest Tajikistan-is something relatively new, which has increased since the arrival of mini-factories (imported from China) enabling the processing of small volumes of cotton. As a result, cotton theft in both Chinese and locally owned fields is more pervasive now than it was under Soviet rule. However, while social networks may hinder theft on locally owned farms, things are different in a setting with less social control, such as on the fields of Chinese agribusinesses, which are often more remote.

While it might be easy for local men to correct, discipline, or warn women, Chinese men face more challenges in doing so. In one locality, local male translators told me their Chinese company had introduced a curfew for its expatriate employees after some of them had been arguing with women in the fields. Instead, the male translators and local male villagers were instructed to patrol the fields in the evenings. Tajik workers told me that Chinese workers-perhaps due to their high turnover rate-are not always well informed about local customs, as arguing with an unknown woman, or even touching her, is not acceptable in Tajikistan.

The language barrier hampers detailed guidance and mutual understanding in the workplace, and the fact that local translators tend to lack experience in farming creates an additional obstacle-at least at the outset. As a result, the verbal contact between Tajik workers (male and female alike) and their Chinese counterparts is limited to fragmented sentences and single terms in a mixture of languages. In one locality, as a Tajik female labourer told me, Chinese workers addressed all women with the Tajik name 'Mariam'. In turn, Tajik women had started calling Chinese men 'Bakha' (the short version of the Tajik name Bakhtiyor). One farmer in another locality explained to me that when Chinese workers are not satisfied with the quality of cotton delivered by local farmers, they say 'khona, khona' ('home, home'), indicating that they find the cotton of inferior quality and will not accept it. 


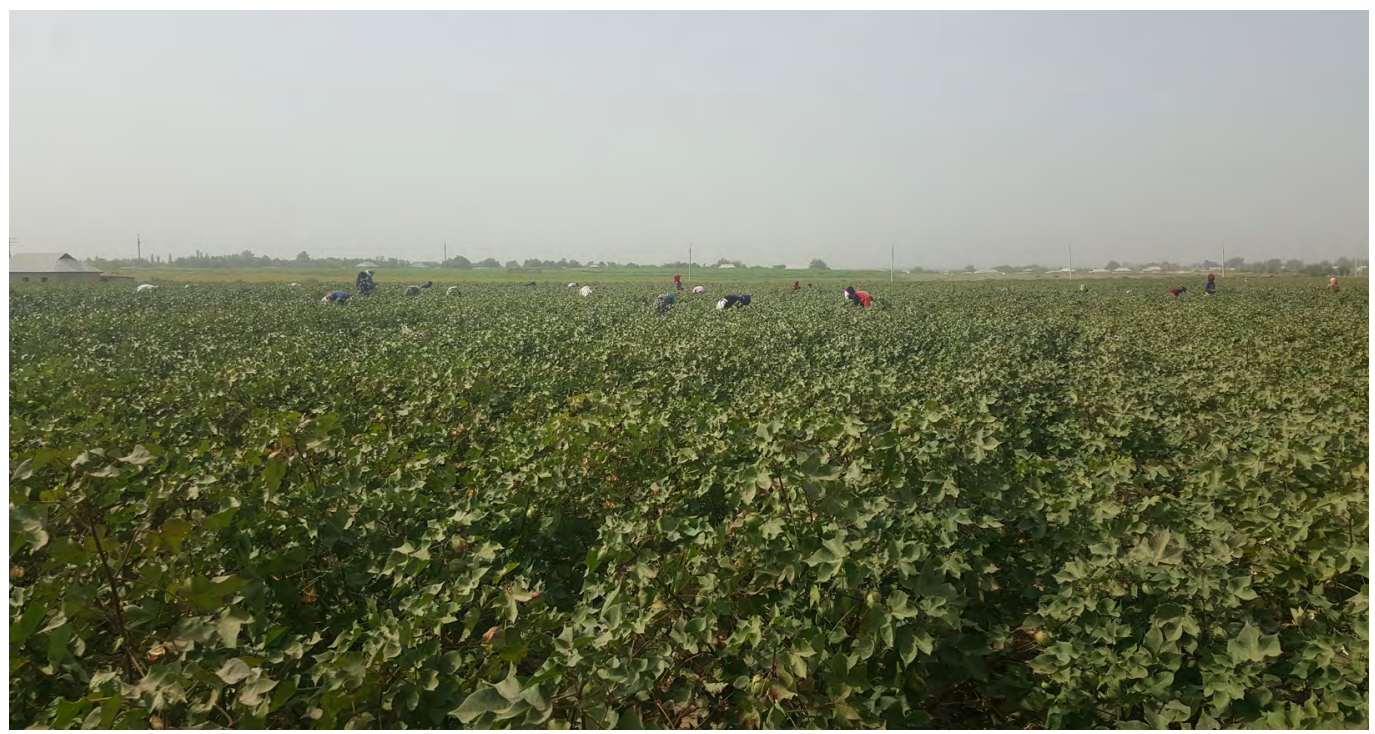

A Tajik female brigade working in the cotton fields of a Chinese-Tajik agribusiness, August 2020. PC: Irna Hofman.

Despite these barriers, workers (both Tajik and Chinese) can also express discontent through their speech. On Chinese company bases, to indicate good work, or bad work, or fixed or broken items, both Chinese and Tajik workers use simple Russian terms, such as 'Plokho, plokho' ('bad, bad') or 'khorosho, khorosho' ('good, good'), with thumbs up or down. In some teams, these words have taken on some ironic connotations. In two instances, when a Chinese man seemed unhappy, or after two Chinese argued with each other, the Tajik workers commented: 'Plokho, plokho, vodka? Vodka?!' This kind of interaction in broken and mixed languages seems reminiscent of the observations of Driessen (2020), who closely interrogated the use of language (pidgin) on Chinese-Ethiopian road-building sites. I also noticed that wordplay and references to cultural differences were common, including nicknames, such as the naming of 'Mr Bean', mentioned earlier; in another locality, local male workers nicknamed a Chinese manager 'the thick' (ghafs) because of his physical appearance. The selective use of such terms and words-presumably not understood by the foreign counterpart-point to wordplay and covert agency.
Rarely do women (or, in fact, workers in general) protest overtly, but local discussions are quite common. Only in one case did I hear about women who mobilised to protest the alleged high levels of pesticides applied by a Chinese company, reporting illnesses, allergies, and even fertility problems. On that occasion, they managed to bring their concerns to the local procurator but were eventually silenced due to elite pressure. Women thereupon refused to continue working. Such a collective protest is rarely seen when the local patriarchal order and social networks are in place, and it contrasts with the more common subtle forms of subversion described earlier.

\section{Probing the Dominant Rhetoric}

Tajik-Chinese gendered encounters take on a blend of characteristics. There is empathy, affection, as well as indifference, fear, and condemnation, but the positive dimensions of appreciation of, and desire for, Chinese individuals and Chinese people 
are often overlooked and downplayed in both rural and urban Tajikistan. Whereas Chinese companies in the country emphasise the win-win of cooperation and investment, most rhetoric as well as literature on China in Central Asia suggests and presumes widespread anti-China sentiment and relegates local actors to the role of passive victims of exploitation. While fully aware of the hardships faced by workers in the fields of rural Tajikistan, I aimed in this essay to probe their agency vis-a-vis their Chinese colleagues and superiors. What I found is that 'the advent of new investors transforms local identities' (Behzadi 2019: 151), albeit in highly diverse ways. There is more ambivalence than often is acknowledged. As Tajik elites reap benefits from Chinese diplomatic initiatives and investment, others attempt to take advantage in various ways, too. This includes Tajik women, who can find subtle ways to challenge domination both in the realm of the extended family and from Chinese employers. Whereas the Soviet and Tajik civil war legacies and contemporary politics partially explain the near voiceless forms of resistance they employ, these women are never entirely powerless (see also Harris 2004).

Tajik women's agency in the interstices of patriarchal order remains overlooked. We need to attend to different forms of agency and the diversity in desires. Yet no-one is completely powerless or unable to gain some self-respect in entanglement. Resistance and agency are expressed and demonstrated for different reasons and in a plethora of ways-sometimes subtle, sometimes outspoken and tangible. While anti-China protests are reported and even tracked nowadays, ethnographic interaction is essential to study the ways in which less-connected and less-privileged actors navigate their environment and express themselves. Furthermore, female empowerment in rural Central Asia has been at the core of the international donor community's activities for many years. While through grants and training women may perceive opportunities to spur their individual household economy, donors' approaches tend to be paternalistic. While I do not ignore the often-exploitative nature of women's work for Chinese agribusinesses, pronounced paternalistic attitudes are absent on the work floor-a situation that may, make women aware of their collective strength and ability to protest exploitative farm work in Tajikistan.

'The agribusinesses described in this essay are officially Chinese-Tajik joint ventures, but in practice they are run by the Chinese side and locally referred to as Chinese. For that reason, I refer to these companies as 'Chinese' in this essay.

I thank Miriam Driessen, Nozilakhon Mukhamedova, and Jaimee Comstock-Skipp, as well as the editors of the Made in China Journal, for their valuable comments. This contribution has benefited from my ongoing research funded by the European Research Council (grant agreement No. 803763). 
This text is taken from Made in China Journal: Volume 6, Issue 2, 2021, edited by Ivan Franceschini and Nicholas Loubere, published 2021 by ANU Press, The Australian National University, Canberra, Australia.

doi.org/10.22459/MIC.06.02.2021.27 